\title{
- Design of UWB Slot Antenna for WBAN Application
}

\section{Sesha Vidhya $\mathbf{S}^{1}$, Rukmani Devi $\mathbf{S}^{2}$, Shanthi $\mathbf{K G}^{3}$, Nowshith Parveen $\mathbf{N}^{4}$}

\section{IJCRR}

Section: Healthcare

ISI Impact Factor

(2019-20): 1.628

IC Value (2019): 90.81

SJIF (2020) $=7.893$

\author{
${ }^{1,3,4}$ Department of Electronics and Communication Engineering, RMK College of Engineering and Technology, Tamil Nadu, lndia; ${ }^{2}$ Depart- \\ ment of Electronics and Communication Engineering, RMD Engineering College, Tamil Nadu, India.
}

\section{ABSTRACT}

Introduction: The essential development of medical science and health care systems has flagged track for the application of the UWB (Ultra Wide Band) antenna. It is combined with material science engineering to provide its service in the Body Centric Wireless Communication (BCWC). The standard operating range of the UWB antenna is from $3.1 \mathrm{GHz}$ to $10.6 \mathrm{GHz}$. The UWB satisfies the maximum requirement of an antenna in bio-medical and bio-apparatus manufacturing.

Objective: The UWB antenna was designed to be more suitable and appropriate for WBAN (Wireless Body Area Network) application with the following characteristics such as low profile, high reliability, high data rate and high efficiency. The quality of living was improved by their applications in the bio-medical productions.

Methods: This proposed structure has a ground and a patch scratched over the surface of the Roger Duroid-5870 substrate with $1.6 \mathrm{~mm}$ thickness. The structure is partially grounded with meta-material to reduce the back-body radiations.

Result: The prerequisite maximum efficiency of about 98\%, greater directivity, minimum SAR (Specific Absorption Rate) value and smaller size for on-body application has been achieved.

Conclusion: Our proposed design yielded a UWB slot antenna with excellent characteristics making it well suitable for on-body communications.

Key Words: UWB (Ultra Wide Band) Antenna, Linear plotting slits, WBAN (Wireless Body Area Networks), SAR (Specific Absorption Rate), Edge feeding, On-body communication

\section{INTRODUCTION}

The drastic evolution of medical science and health care systems has paved the path for the application of UWB. It is merged with material science engineering to provide its service in the Body Centric Wireless Communication (BCWC). These systems have brought down the cost and increased dependability because of their potentially feasible features and applications. Thereby improving the quality of living of the people, by their application in the bio-medical industries. The UWB satisfies the maximum requirement of an antenna in the bio-medical and bio-equipment industries. These antennas provide lower power spectral densities of about $41.3 \mathrm{dBm} / \mathrm{MHz}$ which would manage to provide low to medium data rate for computing applications. Apart from low spectral densities, they are preferred because of their appreciative compact size, lightweight and minimal radioactive standards for avoiding radiation risk. ${ }^{1-3}$
The UWB antenna provides a broad range of frequency with a low SAR value. As the transmission power is low, UWB antennas are most suitable for Wireless Body Area Network. And the communication period is also impulsive this antenna does not affect the human body. In amidst various types of antenna, the microstrip patch antenna is widely used in wireless applications due to its low profile, low cost, lightweight and simple architecture.,

The normal working range of the UWB antenna is from $3.1 \mathrm{GHz}$ to $10.6 \mathrm{GHz}$. Also, the characteristic like low profile, reliability and high performance makes it more suitable and appropriate for WBAN application. ${ }^{6,7}$

Roger Duroid- 5870 is used for the fabrication of substrate which has a permittivity of 2.33. It is laminated uniformly from one plane to the other and provides a constant value over a wide range of frequency. As discussed in the paper

\section{Corresponding Author:}

Ms. S. Sesha Vidhya, Associate Professor, RMK College of Engineering and Technology, India.

E-mail: seshavidhya@rmkcet.ac.in

ISSN: 2231-2196 (Print)

Received: 08.09 .2020
ISSN: 0975-5241 (Online)

Revised: 12.11 .2020
Accepted: 18.12 .2020

Published: 20.03 .2021 
mentioned, the UWB antenna is applicable for bio-medical application as it provides high fidelity, low bit rate and bandwidth. ${ }^{8,9}$

A special material called meta-material is used for the fabrication of the antenna. Due to their macroscopic periodic nature, they are capable of providing low loss, better efficiency and effective bandwidth, thus making it easy to handle. ${ }^{10,11}$ The microstrip patch antenna can provide better performance in off body radiation and making it user friendly, which can also be demonstrated in the open environment along with the real-time application. ${ }^{12,13}$ For a wireless body area network, the SAR value for on body radiation should be less than $1.6 \mathrm{~W} / \mathrm{Kg}$ as per the standardization. ${ }^{14}$ The different slotted or slit shapes have been designed, and also concluded that among all shapes, $\mathrm{S}$ shape is the better most choice for the overall size reduction of the Microstrip antenna. ${ }^{15}$

The problem to be addressed for a reliable on-body application is overcome by providing wide bandwidth small size and low backward radiations. The same is achieved by slotting the structure and implementing partial ground proportionally. The proposed antenna is designed for UWB range in wireless body area network (WBAN) for on-body communication. This antenna uses a linearly plotted slit shape microstrip patch for size reduction and wider Bandwidth. To reduce power consumption and avoid the back radiation the partial ground technique is employed.

The organization of the paper is as follows; the second section presents the material used, design and structure of the antenna, the third section gives simulated results in terms of antenna parameters and the same has been compared with tested results. Finally, the conclusion is presented in the fourth section.

\section{MATERIALS AND METHODS}

The basic design of this antenna is implemented using Linear Plotting Slit structure for improving the bandwidth and for size reduction. ${ }^{18}$ The ground is partially sized with the dimensions of $28 \times 7 \mathrm{~mm}^{2}$ beneath the substrate. Roger Duroid 5870 is used as the substrate material to provide higher efficiency and a larger band range. And the substrate is spread over the surface of $28 \times 33 \times 1.6 \mathrm{~mm}^{3}$ giving it a compact nature. A bidirectional pattern is produced which reduces the power loss thus producing minimal return loss. The edge feeding technique is used to attain impedance matching. Figure 1a displays the front view of the simulated antenna using HFSS.

Figure $1 \mathrm{~b}$ shows the front view of the fabricated Antenna. Overall dimensions achieved by this design are $0.691 \lambda$, $0.823 \lambda$, and $0.039 \lambda$ at the operating frequency of $5 \mathrm{GHz}$. Thus, providing an antenna with smaller dimensions and makes the antenna convenient for the body area network.

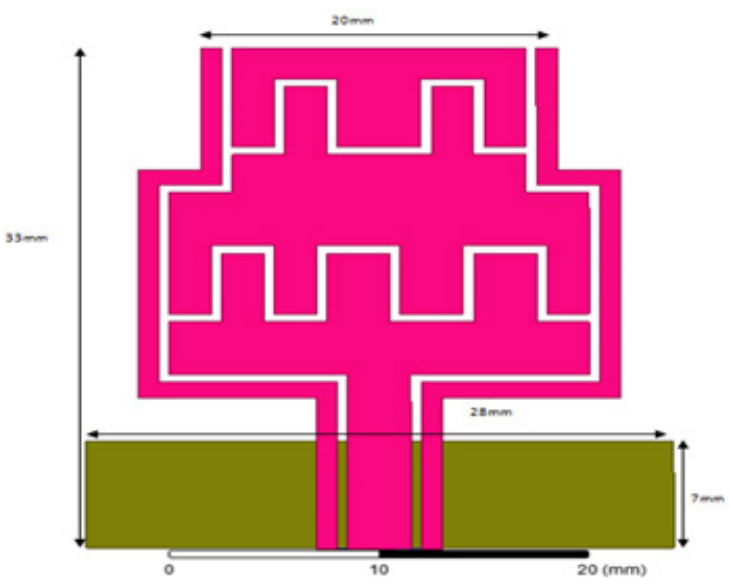

Figure 1a: Front view of the Simulated Antenna.

Table 1 and Table 2 represent the dimensions of the Antenna and Antenna Parameters respectively. The antenna performance characteristics are discussed in the later section.

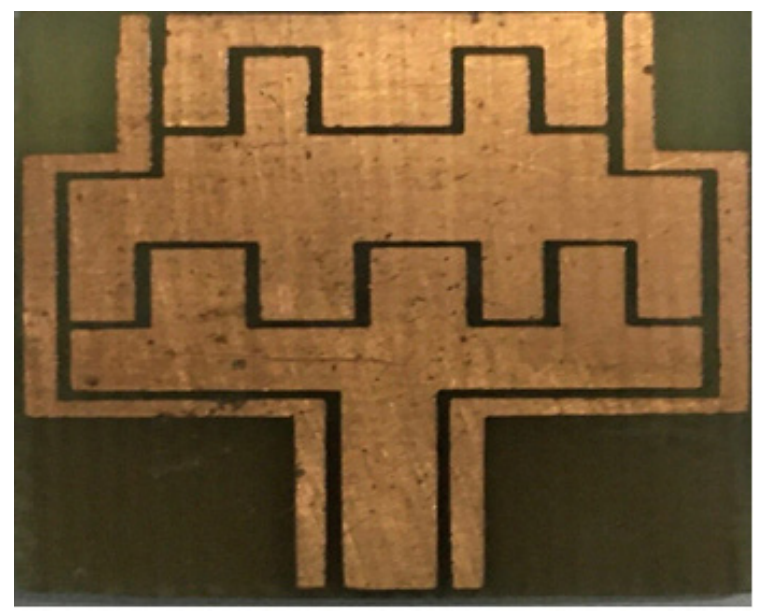

Figure 1b: Front view of Fabricated Antenna.

\section{Table 1: Dimensions of the antenna}

\begin{tabular}{|c|c|c|}
\hline No. & Dimensions & Values(mm) \\
\hline 1. & $\mathrm{~W}_{\mathrm{p}}$ & 23 \\
\hline 2. & $\mathrm{~L}_{p}$ & 23 \\
\hline 3. & $\mathrm{~W}_{\mathrm{g}}$ & 7 \\
\hline 4. & $\mathrm{~L}_{\mathrm{z}}$ & 28 \\
\hline 5. & $\mathbf{h}$ & 1.6 \\
\hline 6. & $\mathrm{~W}_{\mathrm{s}}$ & 33 \\
\hline 7. & $\mathbf{L}_{s}$ & 28 \\
\hline 8. & $\mathrm{~W}_{\mathrm{f}}$ & 1.6 \\
\hline 9. & Lf & 4 \\
\hline
\end{tabular}


Table 2: Antenna parameters

\begin{tabular}{|l|l|l|}
\hline No. & Dimensions & Abbreviation \\
\hline 1. & $\mathrm{~W}_{\mathrm{p}}$ & Width of the patch \\
\hline 2. & $\mathrm{~L}_{\mathrm{p}}$ & Length of the patch \\
\hline 3. & $\mathrm{~W}_{\mathrm{g}}$ & Width of the ground \\
\hline 4. & $\mathrm{~L}_{\mathrm{g}}$ & Width of the ground \\
\hline 5. & $\mathrm{~h}$ & Height of the substrate \\
\hline 6. & $\mathrm{~W}_{\mathrm{s}}$ & Width of the substrate \\
\hline 7. & $\mathrm{~L}_{\mathrm{s}}$ & Length of the substrate \\
\hline 8. & $\mathrm{~W}_{\mathrm{f}}$ & Width of the feed \\
\hline 9. & $\mathrm{Lf}_{\mathrm{f}}$ & Length of the feed \\
\hline
\end{tabular}

\section{RESULT AND DISCUSSION}

The designed Roger Duroid 5870 based UWB antenna is operating at a frequency of $5 \mathrm{GHz}$. The same has been simulated using HFSS software. The simulated $\mathrm{S}_{11}$ plot is shown in figure 2. The return loss is the measure of how well the device or the line are matched and the power reflected from the antenna, at $4.5 \mathrm{GHz}$ the return loss is found to be -16.92 $\mathrm{dB}$. The fabricated antenna is tested and obtained return loss at the operating frequency is found to be $-17.13 \mathrm{~dB}$ at $4.52 \mathrm{GHz},-10.76 \mathrm{~dB}$ at $7.56 \mathrm{GHz}$ and -24.25 at $3.6 \mathrm{GHz}$. The extensive simulation and calibration process produced wider bandwidth trading off between directivity as shown in figure 2. This plot covers the desired band range of UWB frequency operating from 4.13 to $5.18 \mathrm{GHz}$ providing $1.68 \mathrm{GHz}$ as bandwidth.

Thus, better matching between the feed probe and the patch is achieved. It is also seen that due to effective wave designing and feeding technique the bandwidth achieved is $1.68 \mathrm{GHz}$.

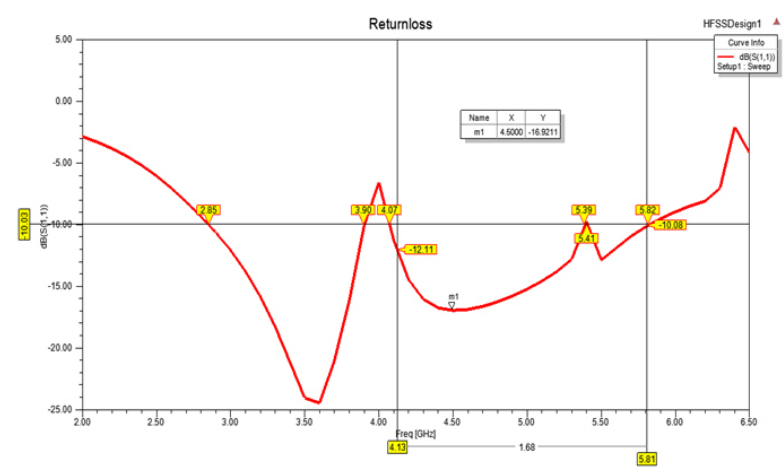

Figure 2: Return loss.

The energy absorbed by the human body when exposed to a radio frequency (RF) electromagnetic field is known as the Specific Absorption Rate (SAR). The average SAR value for a human body is $1.6 \mathrm{~W} / \mathrm{kg}$. The simulated SAR pattern for the designed antenna is shown in figure 3. There is a uniform distribution of deep blue over the patch of the antenna which represents zero SAR value which makes it most suitable for the on-body application. Figure $4 \mathrm{a}$ shows the far-field radiation pattern at $0^{\circ}$. Figure $4 \mathrm{~b}$ shows the far-field radiation pattern at $90^{\circ}$. Figure $4 \mathrm{c}$ shows the far-field radiation pattern at $180^{\circ}$.
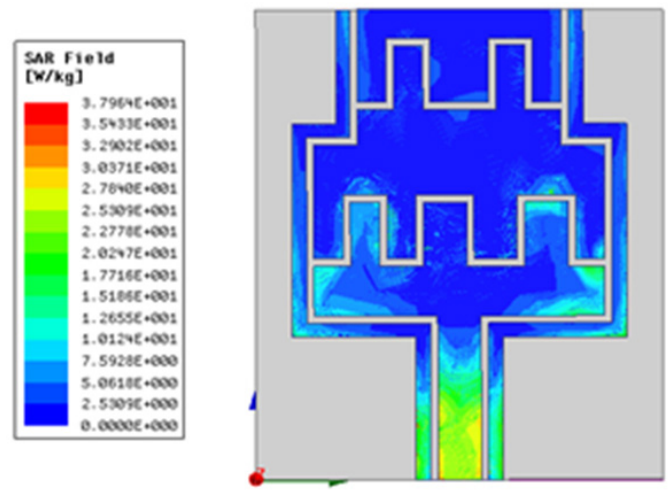

Figure 3: Specific Absorption Rate.
A

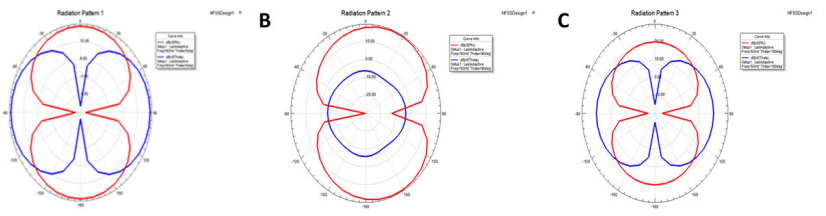

Figure 4: A. The far-field radiation pattern at $0^{\circ}$. B. the farfield radiation pattern at $90^{\circ}$. C. the far-field radiation pattern at $180^{\circ}$.

The term Gain combines antenna directivity and electrical efficiency. The gain performance of the Roger Duroid UWB antenna is shown in figure 5. The graph result shows that the UWB antenna proposed provides a peak gain of $3.23 \mathrm{~dB}$ which makes this antenna more suitable for biomedical application.
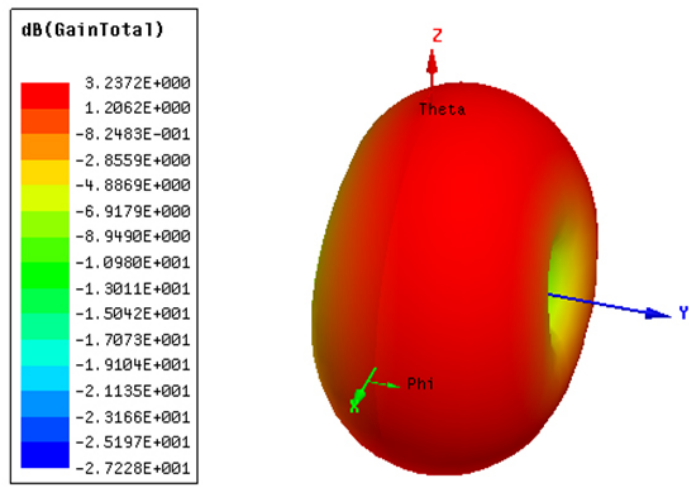

Figure 5: 3D representation of Gain of the Antenna. 
The plot of the gain as a function of direction is bidirectional and hence capable of transmitting and receiving electromagnetic radiation. Directivity is the concentration of emitted radiation in a single particular direction. The Directivity for the proposed UWB antenna is shown in figure 6 . The directivity obtained for this antenna is $3.21 \mathrm{~dB}$.
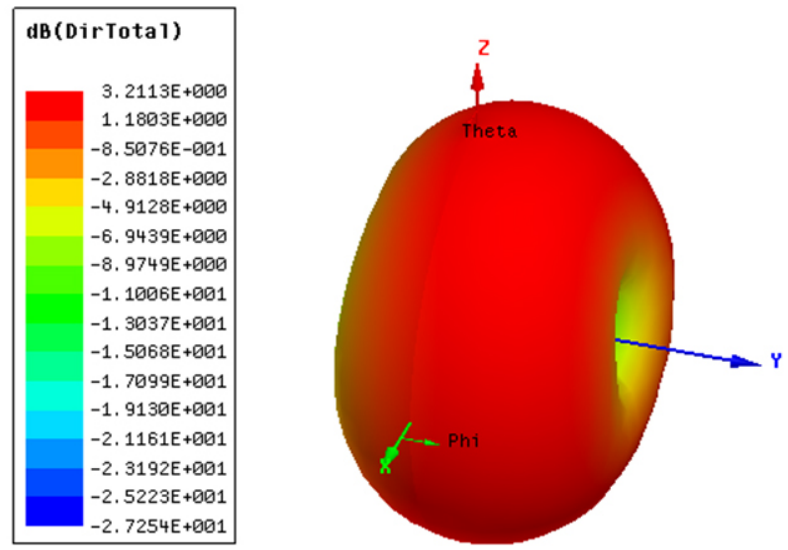

Figure 6: 3D representation of Directivity of the Antenna.

VSWR defines the power reflected from the antenna. The VSWR is found to be 1.33 at a resonant frequency of 4.6 $\mathrm{GHz}$ as shown in figure 7.

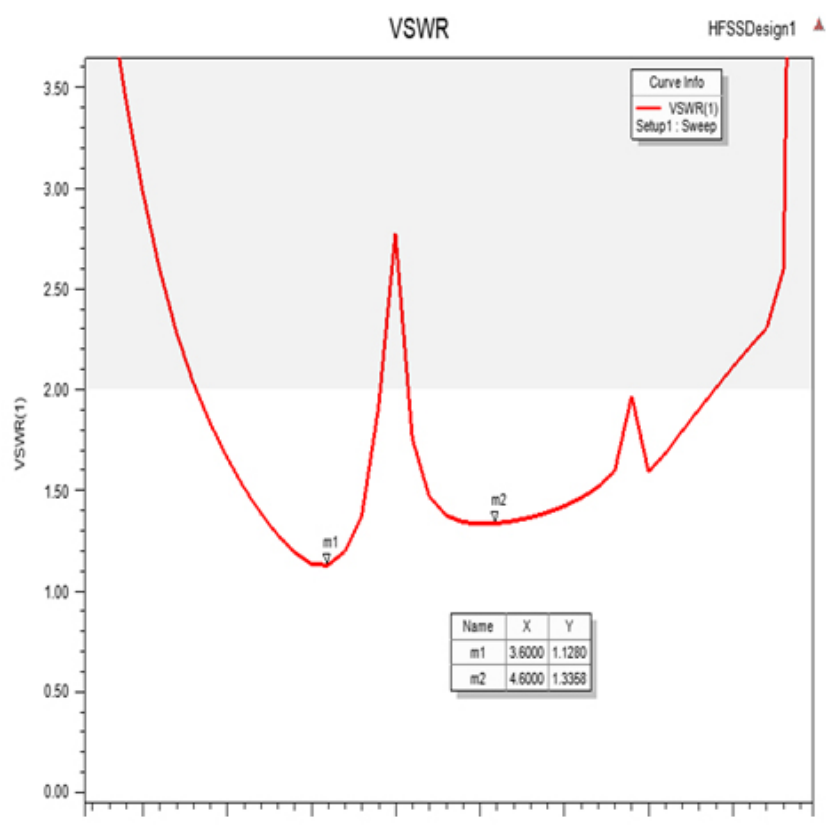

Figure 7: Plot between VSWR vs Frequency.

As a result, better impedance matching has been obtained and more power is delivered to the antenna. The E-field, 3-D radiation pattern of this antenna is shown in the figure 8 .
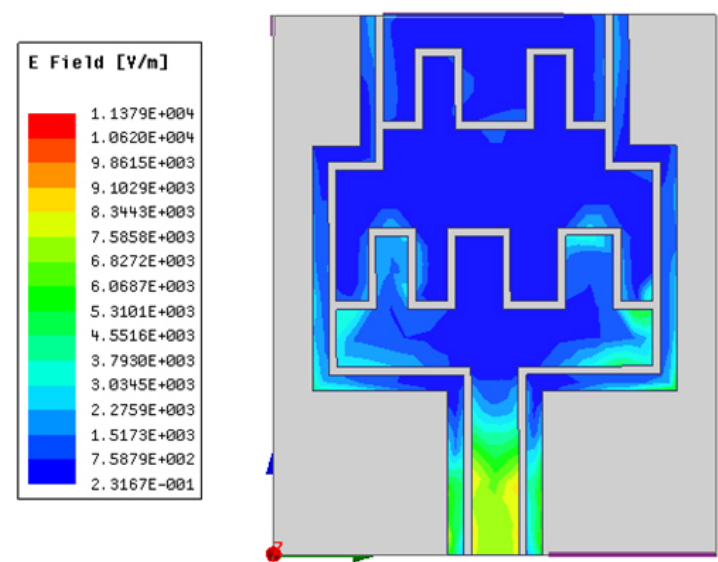

Figure 8: E-field Radiation Pattern.

The $\mathrm{H}$-field 3-D radiation pattern of the proposed antenna is shown in the figure 9.
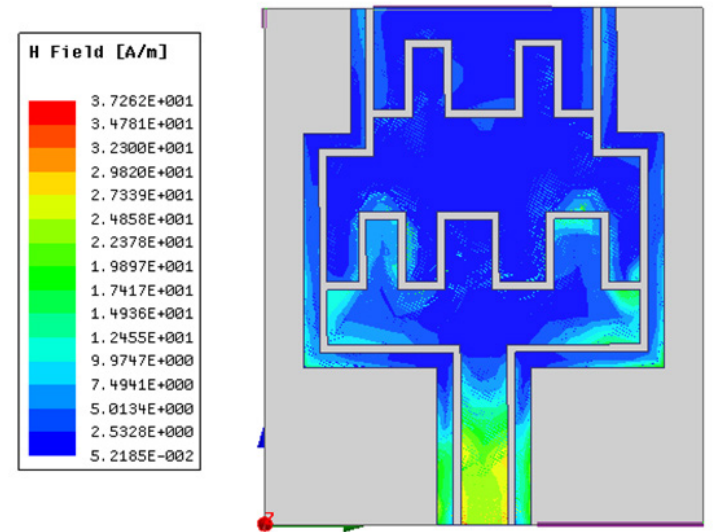

Figure 9: H-field Radiation Pattern.

The J-field 3-D radiation pattern of the proposed antenna is shown in figure 10.
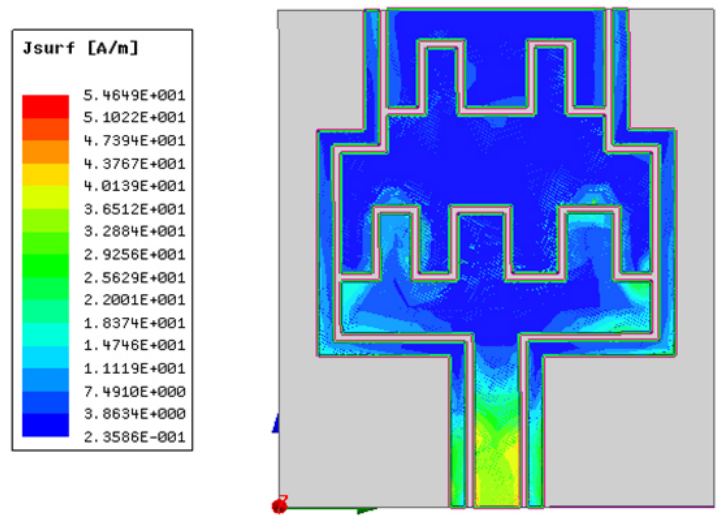

Figure 10: J-field radiation pattern.

And the overall simulated performance characteristic of this proposed antenna is given in table 3 . 
The simulated results as mentioned in table 3 pieces of evidence that the proposed Antenna is furthermost appropriate for on-body Bio-medical applications.

Table 3: Simulated Result
\begin{tabular}{llc} 
SI. No. & PARAMETERS & VALUE \\
\hline 1 & Return loss & $-16.92 \mathrm{~dB}$ \\
2 & Bandwidth & $1.68 \mathrm{GHz}$ \\
3 & SAR & $0.002 \mathrm{~W} / \mathrm{kg}$ \\
4 & Gain & $3.23 \mathrm{~dB}$ \\
5 & Directivity & $3.21 \mathrm{~dB}$ \\
6 & VSWR & 1.33 \\
7 & Efficiency & $98 \%$ \\
\hline
\end{tabular}

\section{CONCLUSION}

The optimal pulse shaped patches and partially slotted ground led to attaining a satisfactory wideband frequency of $1.68 \mathrm{GHz}$ and minimum SAR required for the antenna to be concerned in the Bio-medical applications. Also, the proposed antenna radiates with an efficiency of $98 \%$ and a return loss of $-16.4 \mathrm{~dB}$. These crucial factors empower this antenna idyllic for on-body WBAN applications.

\section{ACKNOWLEDGEMENT}

Authors acknowledge the immense help received from the scholars whose articles are cited and included in references to this manuscript. The authors are also grateful to authors/ editors/publishers of all those articles, journals and books from where the literature for this article has been reviewed and discussed.

\section{Conflict of Interest: NIL}

Source of Funding: NIL

\section{REFERENCES}

1. Sesha VS, Rukmani D, Shanthi KG. Design Trends in Ultra Wide Band Wearable Antennas for Wireless On-Body Networks. ARPN J Engi Appl Sci 2017; 12(9):2782-2790.
2. Poffelie LAY, Soh PJ, Yan S, Vandenbosch GAE. A High Fidelity All Textile UWB Antenna with low back radiation for off body WBAN Application. IEEE Transac Anten Propag 2016;64(2):757-760.

3. Ahmed F, Hasan N, Md. Chowdury HM. A Compact Low-profile Ultra Wideband Antenna for Biomedical Application. Cox's Bazar, Bangladesh 2017.

4. Wang J C, Lin E G, Leach M, Wang Z, Manand K L Huang Y. Conformal Wearable Antennas for WBAN Application. IMECS, Hongkong 2016; 2.

5. Samal P B, Soh P J, Vandenbosch G A E. UWB All-Textile Antenna with full Ground Plane for off-Body WBAN Communication. IEEE 2016.

6. Hraga H I, See C H, Abd-Alhameed R A, Mcewan N J. Miniaturized UWB Antenna for a wireless Body Area Network. Loughborough, UK. 2012.

7. Alomainy A, Hao Y, Parini CG, Hall PS. Comparison between two Different Antennas for UWB on-body Propagation Measurements. IEEE Antennas Wireless Propagation Letters 2005;4:31-34.

8. Alomainy A, Sani A, Rahman A, Santas J G, Yang H. Transient Characteristics of wearable antennas and radio propagation channels for UWB body-centric wireless communications. IEEE Transac Anten Propag 2009;57(4):875-884.

9. Biswas A, Islam A J, Al-Faruk A, Alab S S. Design and Performance Analysis of a Microstrip Line-fed On-Body Matched Flexible UWB Antenna for Bio Medical Application. Cox's Bazar, Bangladesh 2017.

10. Dong Y, Itoh J. Metamaterial-Based Antennas. IEEE Journals and Magazines 2017.

11. Behera B R, Suraj P. Performance Analysis of Microstrip Patch Antenna with Metamaterial and Genetic Algorithm. ICIIS.2016.

12. Dumanli S, Sayer L, Mellios E, Fafoutis X, Hilton G S, Craddock I J. Off-Body Antenna Wireless Performance Evaluation in a Residential Environment.2017;65(11).

13. Gajanan V. Wasalwar, Wasnik D S. Reliability of Physical Examination and Electrocardiogram in Determination of Acute Myocardial Infarction: A Hospital Based Study. Int J Curr Res Rev 2020;12(19).

14. Soh P J, Vandenbosch G A E, Wee F H, Bosch A V D, Vazquez M M, Schreurs D. Specific Absorption Rate (SAR) Evaluation of Textile Antennas.Germany:1-21.

15. Nasimuddin P, Zhi NC, Xianming Q. Circularly Polarized Slotted/Slit-Microstrip Patch Antennas. Microstrip Anten 2015;24:341-360. 